\title{
New rock art discoveries in the Kurnool District, Andhra Pradesh, India
}

Paul S.C. Taçon ${ }^{1}$, Nicole Boivin ${ }^{2}$, Jamie Hampson ${ }^{3}$, James Blinkhorn $^{2}$, Ravi Korisettar ${ }^{4} \&$ Michael Petraglia ${ }^{2}$

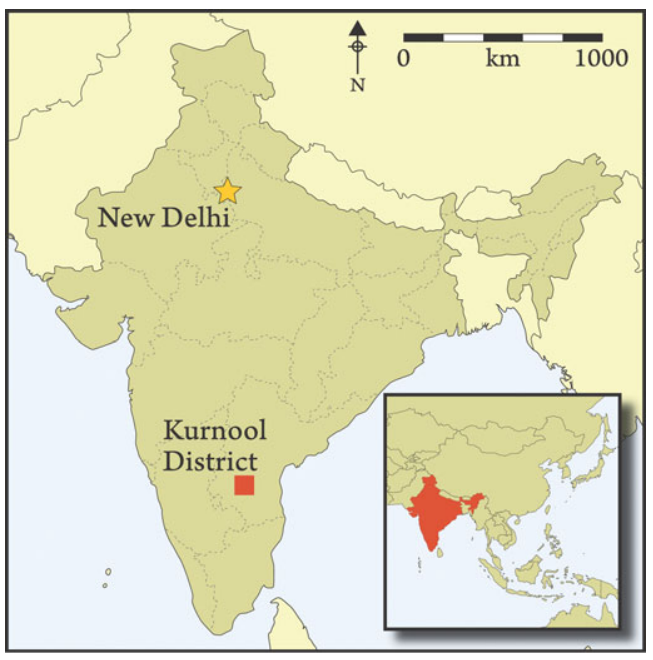

The authors have surveyed the little known paintings of the Kurnool area in central south India, bringing to light the varied work of artists active from the Palaeolithic to the present day. By classifying the images and observing their local superposition and global parallels, they present us with an evolving trend - from the realistic drawings of large deer by hunter-gatherers, through the symbolic humans of the Iron Age to the hand-prints of more recent pilgrims and garish life-size modern 'scarecrows'. Here are the foundations for one of the world's longest sequences of rock art.

Keywords: India, Kurnool, rock art, Jwalapuram Locality 9, Katavani Kunta 1, paintings

\section{Introduction}

India has a vast amount of rock art of global significance (Bednarik \& Chakravarty 1997), consisting mainly of paintings and petroglyphs. Initial investigations began in the late $1800 \mathrm{~s}$ (e.g. Cockburn 1899; Franke 1902) but most research has focused on north and central India (e.g. Brooks \& Wakankar 1976; Neumayer 1983, 1992, 1993; Chakravarty 1984; Mathpal 1984; Pandey 1992; Ghosh 1998; Pradhan 2001; Bednarik 2002; Chakraverty 2003). However, earlier finds from the south (e.g. Gordon 1951; Allchin 1963) have more recently been followed up by investigations which demonstrate that south India also possesses

1 School of Humanities, Gold Coast campus, Griffith University, Qld 4222, Australia (Email: p.tacon@griffith.edu.au)

2 School of Archaeology, University of Oxford, 36 Beaumont Street, Oxford OX1 2PG, UK

3 Department of Archaeology, University of Cambridge, Downing Street, Cambridge CB2 3DZ, UK

4 Department of History and Archaeology, Karnatak University, Dharwad 580 003, India

Received: 12 December 2007; Revised: 1 October 2009; Accepted: 31 December 2009 


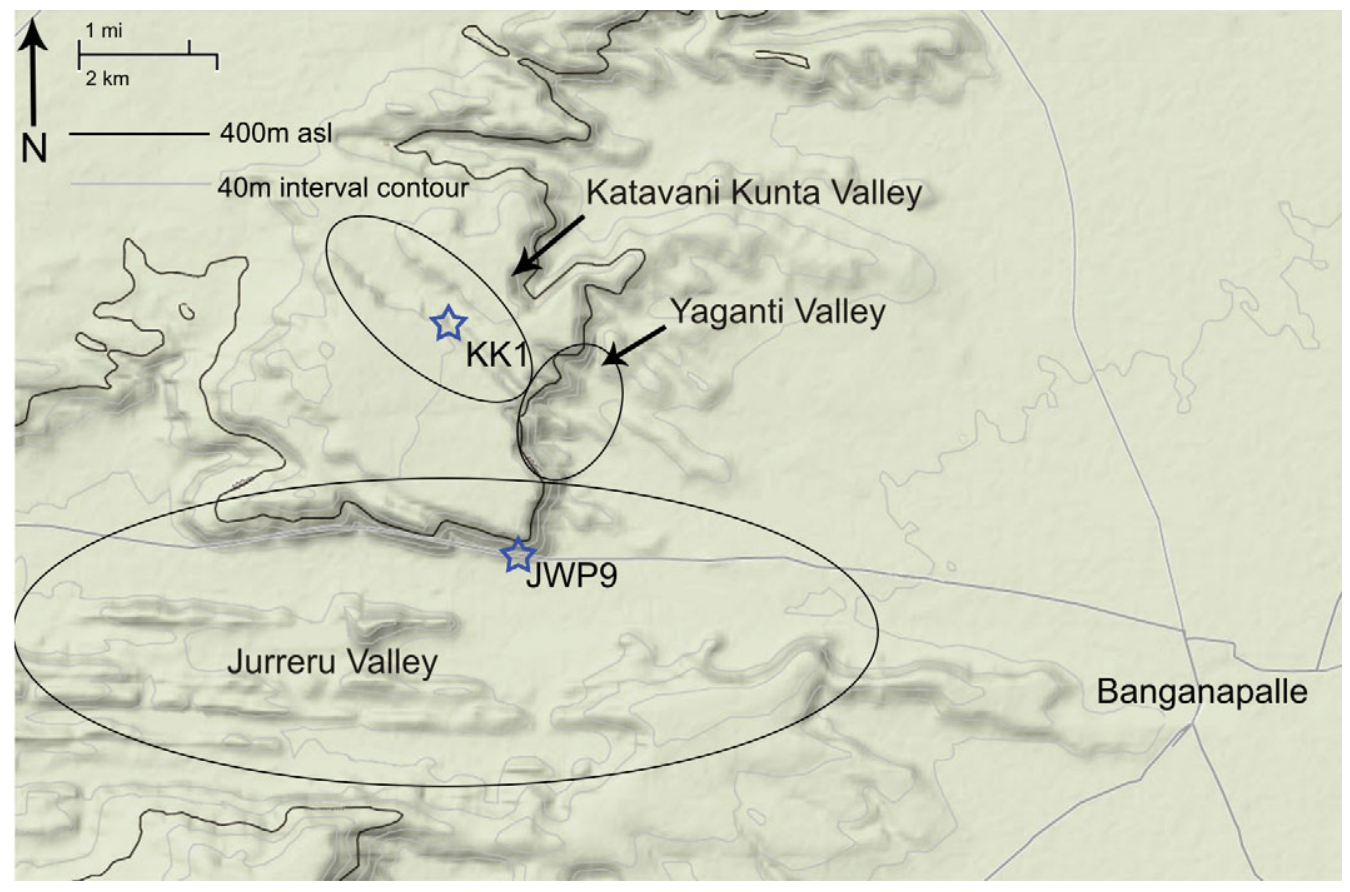

Figure 1. Map showing the location of Banganapalle, south-central India, and the river valleys explored.

a wide range of rock art (e.g. Allchin \& Allchin 1994-95; Mathpal 1998; Chandramouli 2002, 2003; Sridhar 2005).

For several years Boivin and colleagues have conducted rock art research in various parts of south India, beginning on the Deccan Plateau (Boivin 2004; Boivin et al. 2007) and more recently in the Kurnool area (Boivin et al. 2009; Petraglia et al. 2009b). In this paper we report on the significance of recently recorded paintings of animals, human-like figures and other designs from sites in the three valleys of Katavani Kunta, Yaganti and Jurreru near the village-town of Banganapalle, Andhra Pradesh (Figure 1).

The rock art sites are located in an archaeologically rich area noted for the highly significant Palaeolithic deposits at Jwalapuram (Clarkson et al. 2009; Petraglia et al. 2007, 2009a \& b) as well as an abundance of varied Holocene sites, including those of huntergatherer, Neolithic and Megalithic peoples (Allchin 1963; Murty 1985, 1992, 2003b; Blinkhorn 2008; Petraglia et al. 2009b). Field survey since 2003 has located 63 rock art sites in the three valleys of the Kurnool area sampled, but there are many valleys and hilltops that have yet to be studied (see also Boivin et al. 2009). Several different styles of rock art associated with various time periods have been identified and are outlined below.

\section{The Kurnool valleys}

Chandramouli (2002: 92-141, 2003) documented a number of pictograph sites within $30 \mathrm{~km}$ of Kurnool, especially near Kethavaram. The 2007 survey was focused on the three adjacent valleys of Jurreru, Katavanti Kunta and Yaganti (Figure 1), and was aimed at better 


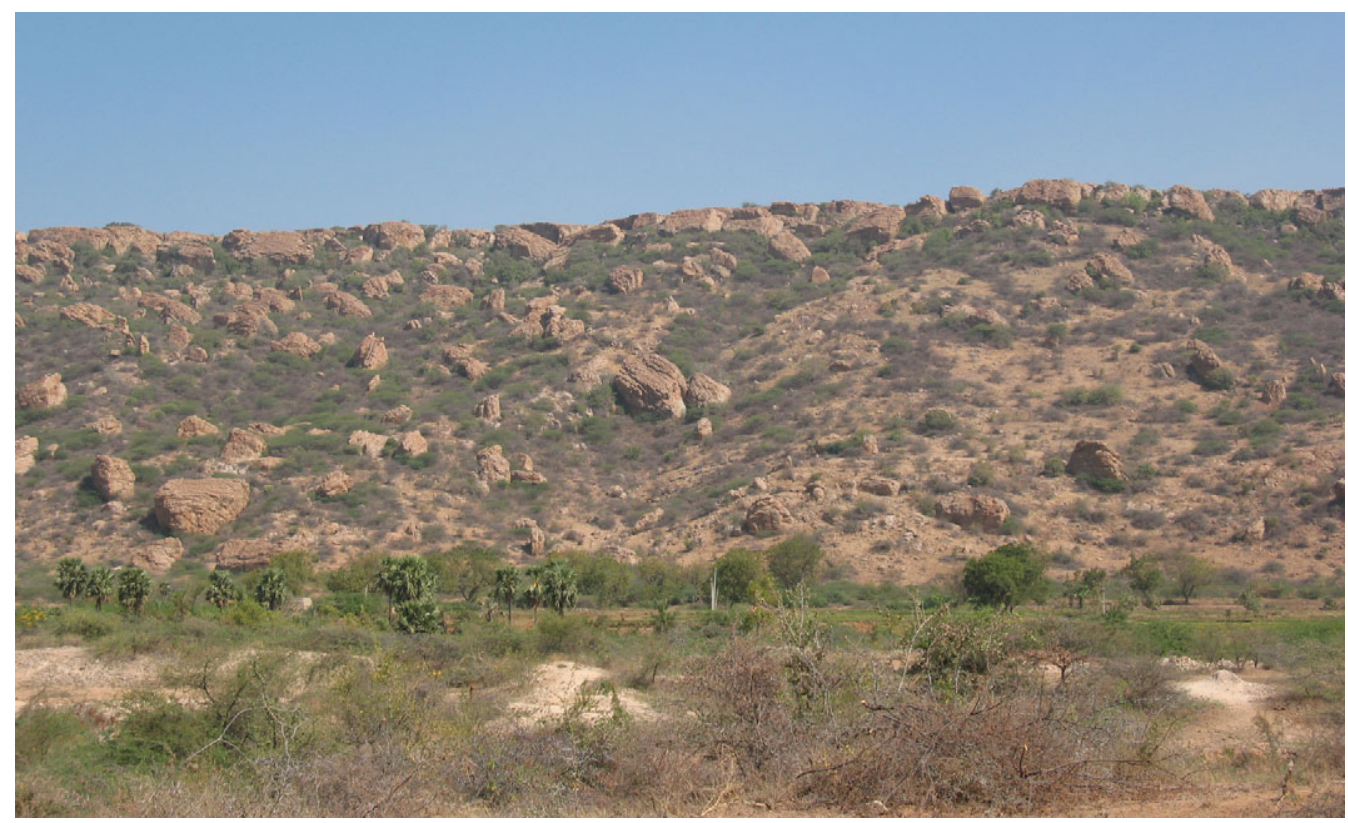

Figure 2. The Jurreru Valley where five rock art sites were documented.

understanding the distribution of sites within the landscape, and their correlation to surface archaeology. Detailed recording at a number of key sites took place in early 2009.

The Jurreru Valley (Figure 2) is steep-sided but relatively wide, and runs along an approximate east-west axis. Five rock art sites have been identified on its northern slopes. Most of the paintings, in red or white, are found on the southern overhangs of the variously sized quartzite boulders that litter the limestone slopes. These boulders are derived from the quartzite escarpment some $300 \mathrm{~m}$ above the valley floor. All but one of the shelters bearing rock art is on the lower slopes of the hill. This valley contains the excavated site of Jwalapuram Locality 9, which dates to 35000 years ago, and also has paintings that were examined in our survey (see below).

Katavani Kunta (Figure 3) is an upland valley that cuts into the quartzite plateau; it runs on a north-west to south-east axis and lies above the Jurreru Valley. It is significantly smaller in size than Jurreru, but contains many more quartzite boulders and painted sites, most of which are found on the lower slopes of the valley, often close to the long-travelled dirt road that winds along the valley floor. A total of 50 sites were found here. Today, the valley lies on a pilgrimage route between two Hindu temples, one of which stands at the south-east entrance to the valley, and some 13 sites in the valley appear to relate to contemporary or recent Hindu religious activities. These sites are located on both the western and eastern sides of the valley, close to (and facing) the road. Another 37 sites contain a distinctive corpus of predominantly red images, and these sites face the valley floor, mostly from the west of the road. The valley has numerous rockshelters formed by low escarpment edges, quartzite boulders piled on scree slopes and eroded boulders sitting on parts of the valley floor. Geologically, the valley is within the Cuddapah Supergroup, a crescent-shaped basin 


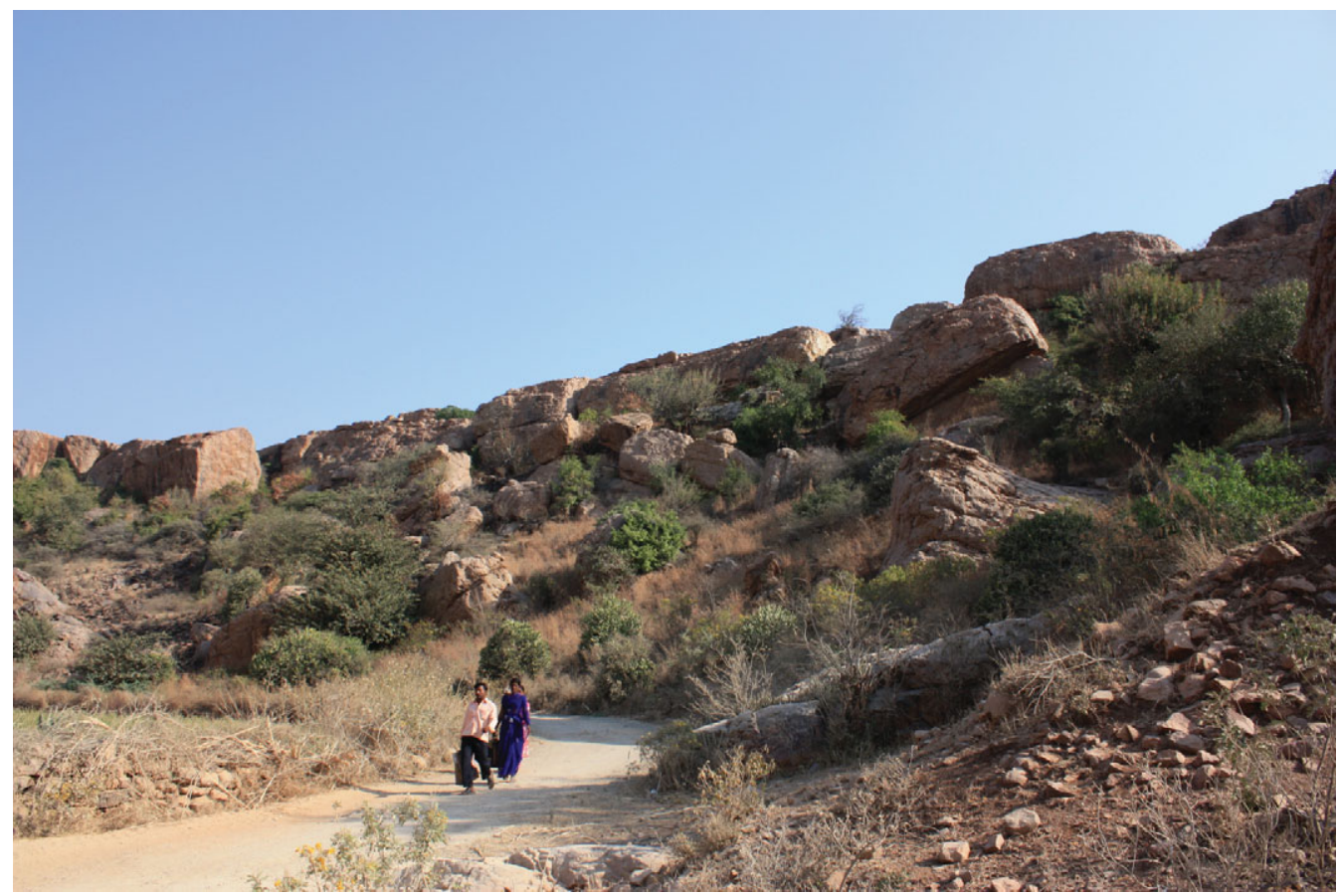

Figure 3. The Katavani Kunta Valley has at least 50 rock art sites.

of Proterozoic age (Gupta et al. 2003). Rockshelter KK1 (below) has provided the best rock art sequence in the area to date.

Yaganti Valley is a subsidiary valley to Katavani Kunta, and also runs along a north-west to south-east axis. All but one of the eight rock art sites in the valley are on quartzite boulders relatively high up the valley's eastern limestone slopes, not far from the Yaganti Hindu temple to the west. Most of the paintings are in red, but some are also in white and black.

\section{Paintings examined: KK1 and JWP 9}

The KK1 rockshelter (Figure 4) is formed by a large sloping boulder resting on a second rounded boulder just up from the valley floor. The shelter measures $14 \mathrm{~m}$ in length, is up to $6.9 \mathrm{~m}$ deep and reaches a height of $7 \mathrm{~m}$. The painted panel is $11.1 \mathrm{~m}$ long and rises to $3.85 \mathrm{~m}$ in the middle, tapering to less than $1 \mathrm{~m}$ at either end. The site faces roughly north at $20^{\circ}$ and little sunlight reaches the paintings, one of the reasons that this site is better preserved than others. With 92 identifiable rock paintings (and one indeterminate) it is the second largest collection of the 63 sites of the Jwalapuram-Katavani Kunta-Yaganti complex. Its diverse subject matter and superimpositions help establish a chronological sequence for the area.

There were three main phases of painting at KK1: a naturalistic phase, mostly with figures in outline but some with a light wash of red infill, a larger solid red more abstract phase and a final phase when large outline animal and human-like figures were produced. There are no stencils or engravings at the site but there is a group of three (possibly accidently produced) 


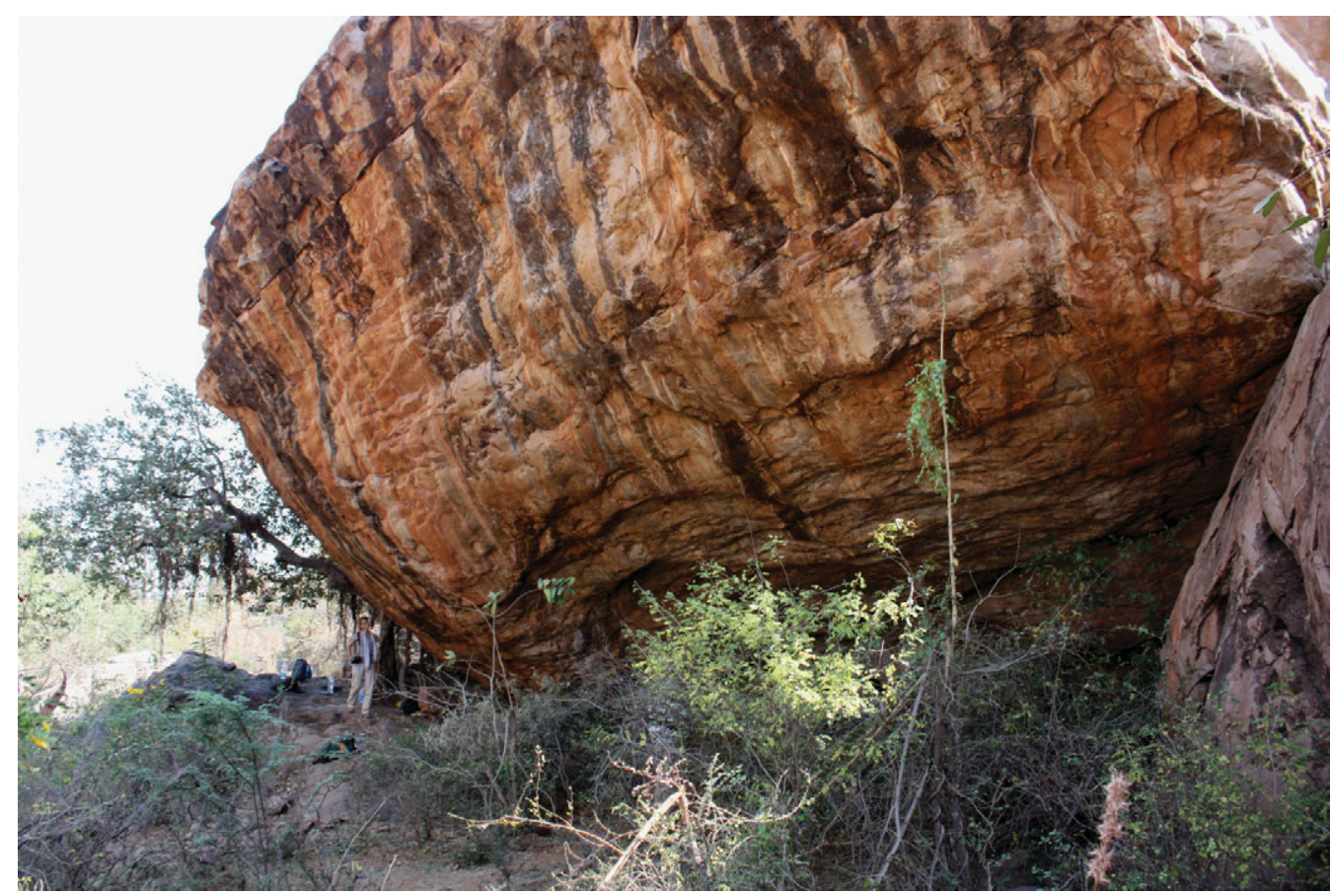

Figure 4. The KK1 rockshelter.

red fingertip prints on a horizontal piece of the wall facing the floor and below some of the paintings.

Altogether there are 20 early naturalistic drawings of animals and humans in Phase I, four semi-naturalistic animals from a possible later sub-phase, two with patterned infill; one set of fingertip prints; 63 red solid and geometric figures in Phase II, and two large outline animals (boar or bear) and two outline human-like figures, one of which is upside down in Phase III, with one indeterminate design. Phase I images were found only at the west end of the rockshelter, while those of other phases were widely distributed.

The Phase I red outline and wash paintings consist of small groups of wild animals, mostly deer (Figure 5) and gazelle, and small groups of profile human-like figures facing the same direction (Figure 6). All depictions of animals are also in profile and when in small groups these face the same direction. At the far west end of the shelter the three red outline deer appear to have been made at the same time and are placed as if the two males are following the female. The red wash deer and gazelle are on one side of a large natural hollow while the outline deer and human-like figures are on the other side. As with many of the deer, the human figures appear to have been purposely arranged in groups.

The solid figures (Figure 7) from Phase II, on the other hand, are much larger and are arranged quite differently. They also are usually somewhat lighter in colour. Sometimes there are groups of three human-like figures or back-to-back human-like solid infill paintings. There are also groups of solid human-like figures facing different directions and human figures associated with diamond designs, one of which has this pattern painted on either 
New rock art discoveries in the Kurnool District, Andhra Pradesh, India

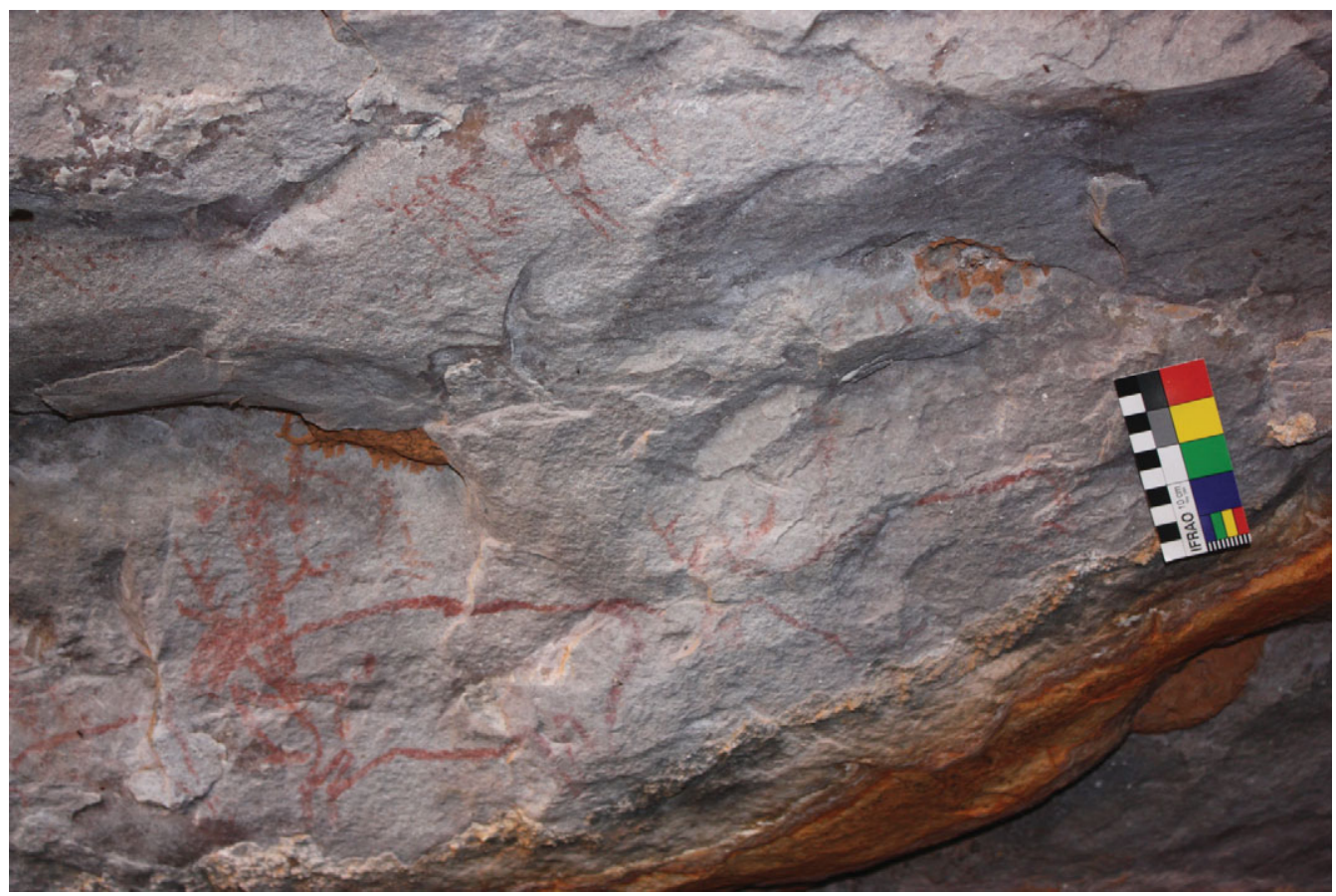

Figure 5. KK1 naturalistic outline deer.

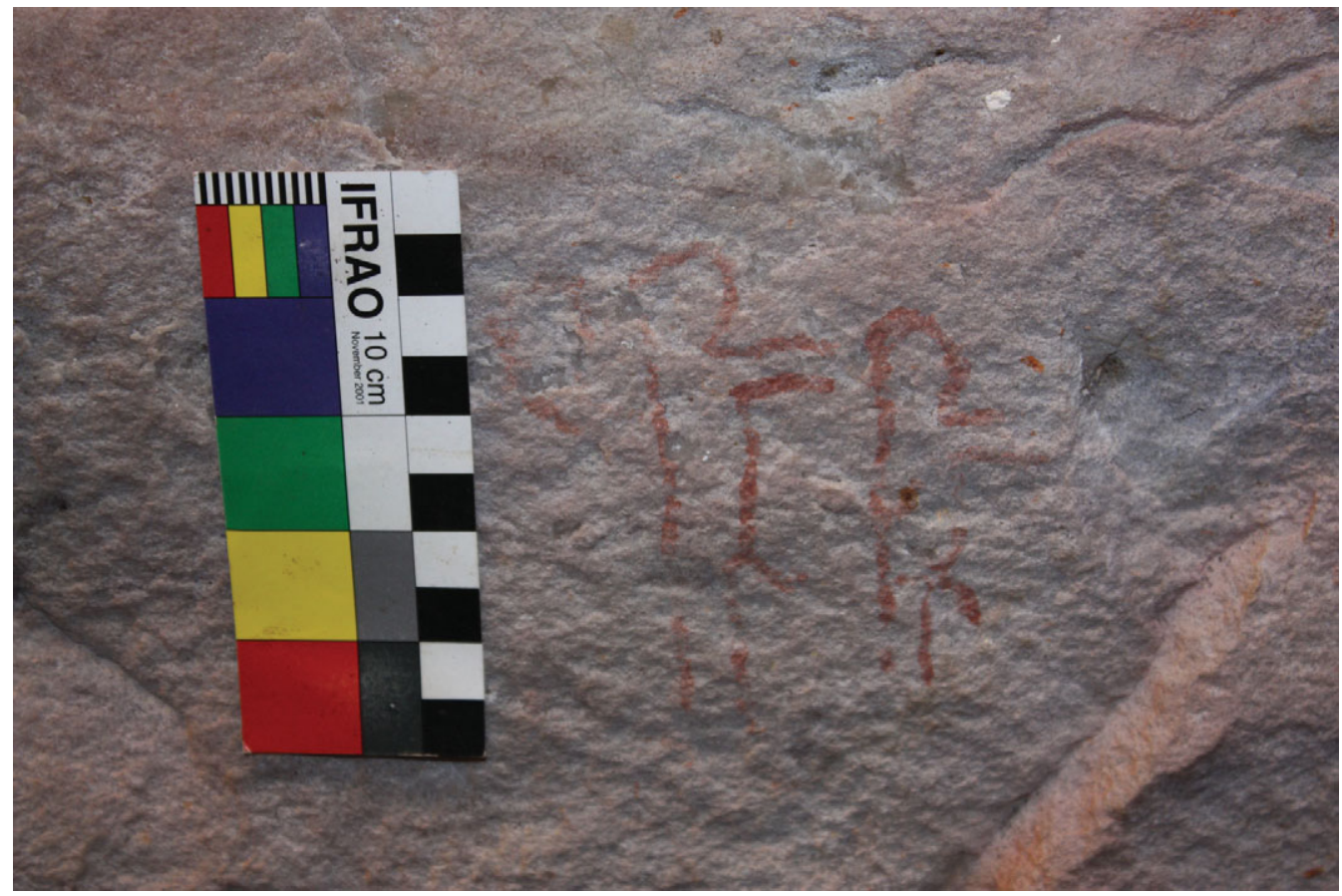

Figure 6. KK1 naturalistic outline profile human-like figures. 


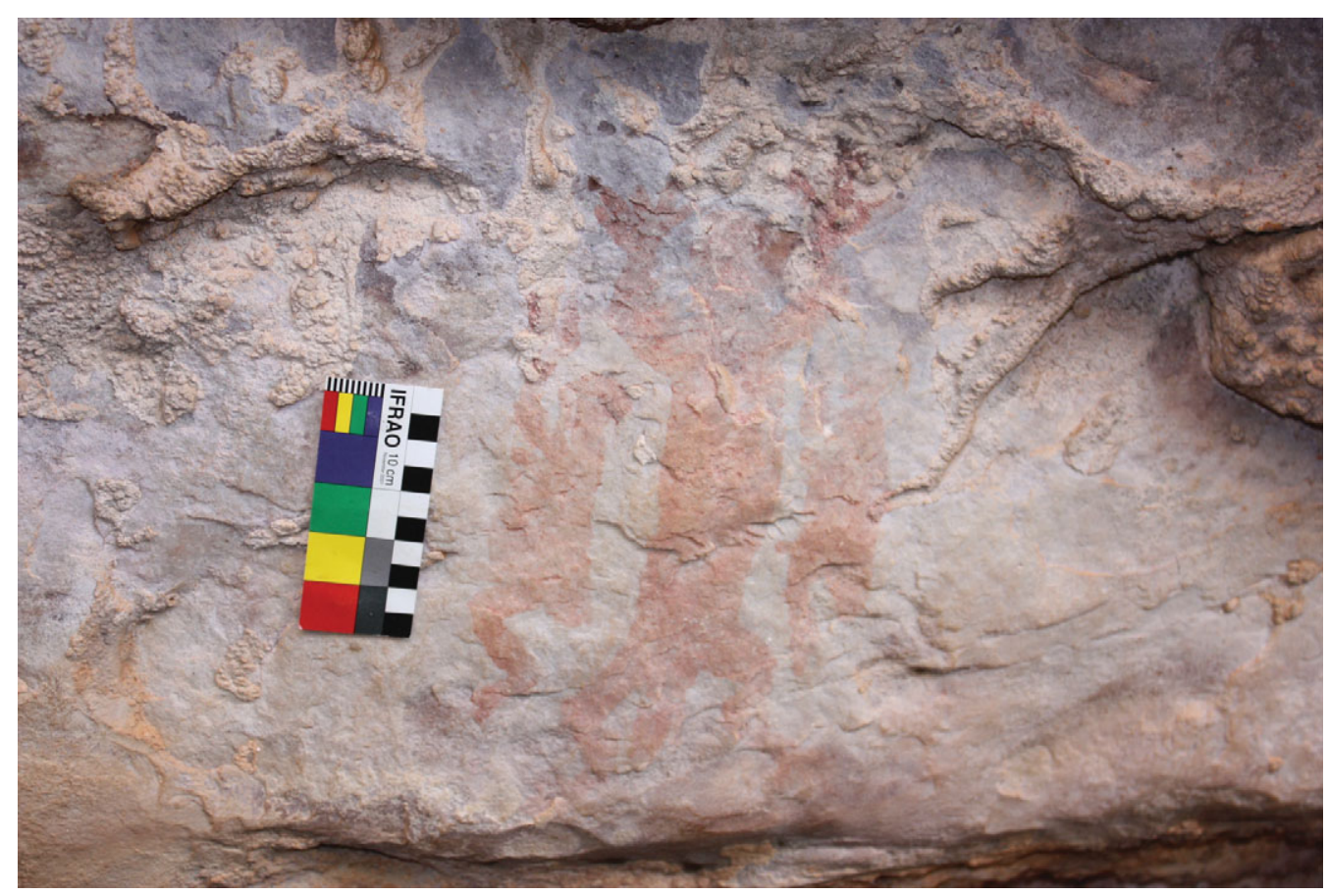

Figure 7. KK1 solid red human-like figures that are part of a theme repeated at other sites.

side of it (Figure 8). The solid phase is also associated with lots of other geometric designs, such as circles and ovals, painted in various parts of the shelter. Animals include some domesticated species, such as a dog associated with a line of four goats. Wild animals are mostly lizards (including monitor) and fish, with a few depictions of boars that could be either wild or domesticated. At the western end of KK1 a solid red human-like figure is clearly superimposed over a naturalistic outline stag (Figure 9), one of the site's most important superimpositions (see also Petraglia et al. 2009b).

KK1 imagery can be found at a number of other sites in the area, although the small early naturalistic outline paintings are so far unique to this site. The deer depicted in the early naturalistic outline style are most likely Sambar (Cervus unicolor), India's largest deer, and/or Chital (Axis axis). They have the greatest range across India and frequented environments similar to those that once existed in the Kurnool area (Mathpal 1993: 6; Murty 2003a: 22). In 1993 over 80 sites in India were found to have deer depicted in them, with Sambar found in half and Chital in even more (Mathpal 1993: 12).

Jwalapuram Locality 9, in the Jurreru Valley, consists of a large quartzite boulder with a sloping exposed wall that provides some shelter (Figure 10). The boulder is about $20 \mathrm{~m}$ long by $10 \mathrm{~m}$ wide and $10 \mathrm{~m}$ high and is situated about $5 \mathrm{~m}$ above the road to Patha Padu village. The site was excavated between 2003 and 2009 (see Clarkson et al. 2009). It dates to 35000 years ago and is considered one of the oldest sites in south India with microliths. Human remains, limestone and bone beads and faunal remains were found in 
New rock art discoveries in the Kurnool District, Andhra Pradesh, India

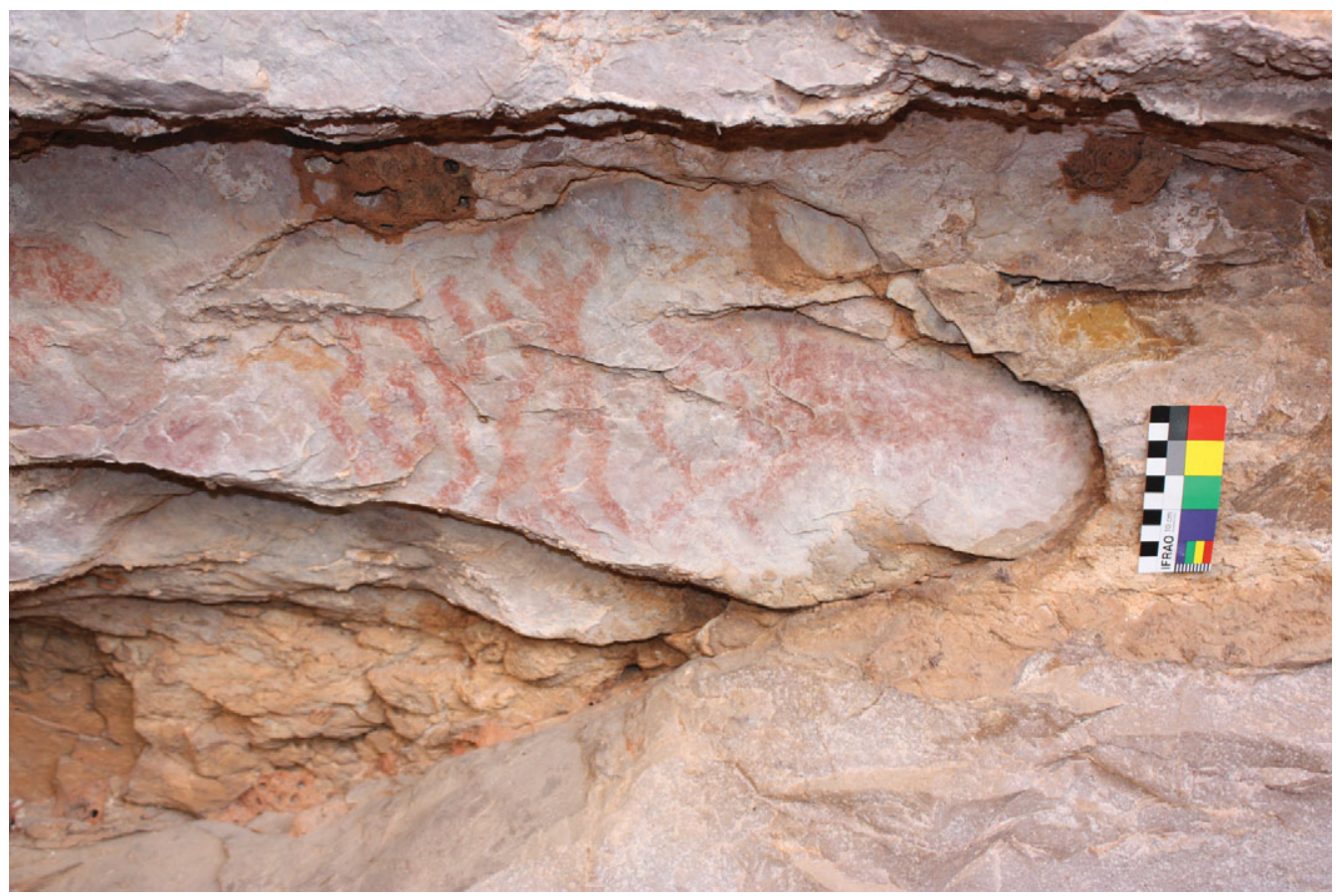

Figure 8. A diamond or lozenge pattern design found at KK1 has counterparts across India. Here it was placed on either side of a solid red figure.

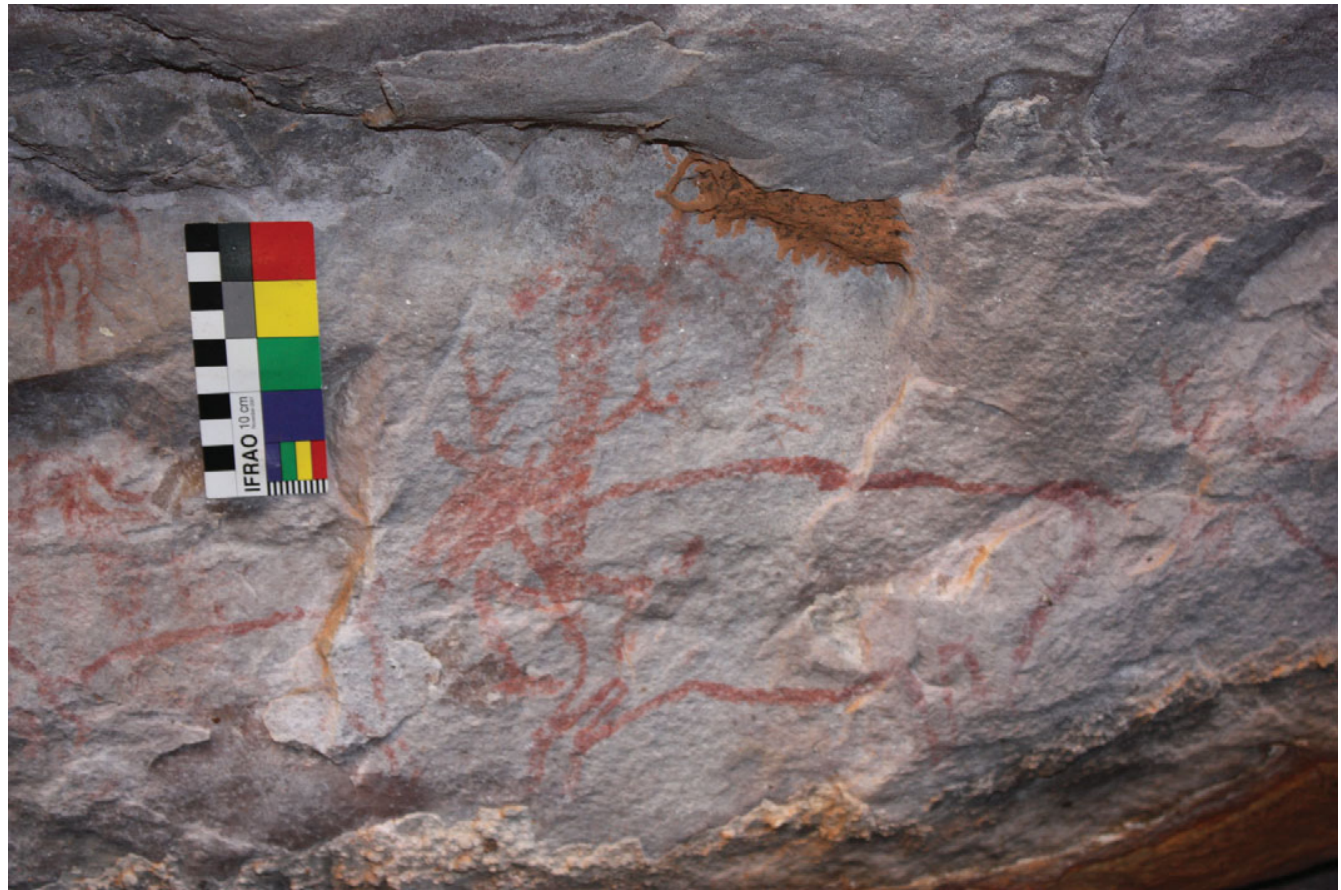

Figure 9. At the western end of KK1 a solid red human-like figure is clearly superimposed over a naturalistic outline deer. 


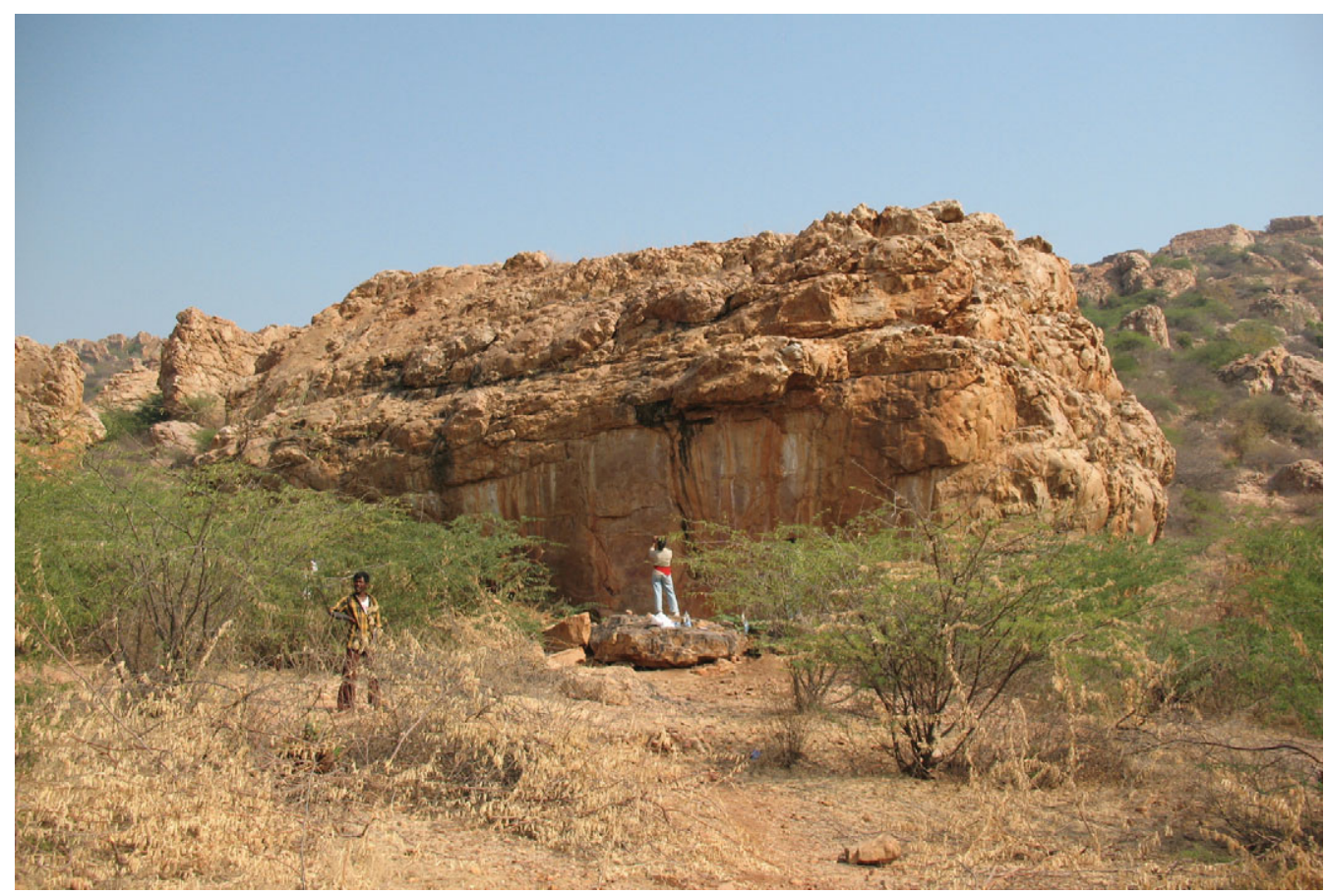

Figure 10. Jwalapuram Locality 9 rockshelter is heavily exposed to the sun so older rock art does not survive well.

the excavation. Many ochre fragments were recovered from Stratum C, dated to between c. 15000 and 11000 BP.

The painted panel, with excavated deposit below, faces south-south-west at $203^{\circ}$. Fourteen faded figures have been discerned, including a red outline elephant (the largest approximately $1.7 \mathrm{~m}$ long and $1.2 \mathrm{~m}$ high), a large light red outline animal (probably a hump back cow, with a stick figure and other infill added later; $1.0 \mathrm{~m}$ long and $0.6 \mathrm{~m}$ high), two red outline and line infill unidentified quadrupeds, two solid red human-like figures, a partial solid red human figure and a solid red back-to-back human figure motif. There are also six geometric designs consisting of three solid red geometrics (2 ovals, spade), two outline geometric figures (purple rectilinear; purple-red crescent) and a complex red line design.

No early naturalistic paintings have been found at Jwalapuram, but given the amount of ochre recovered from various levels of the excavation, including Pleistocene layers (Clarkson et al. 2009), it is probable many more paintings once adorned the wall. Their survival may have been affected by the high degree of exposure to sun and rain.

\section{Sequence}

Most rock art of the Kurnool area consists of paintings but there are also a few sites with engravings of differing styles and ages, a few hand stencils and hand prints, rare drawings, and very recent re-outlining of older art. Attempts to date the Kurnool rock art corpus have primarily focused on relative dating and dating using associated archaeological remains. 
A detailed analysis of KK1 and JWP9 imagery and that recorded at the other 61 sites suggests there were at least five main phases of art activity associated with varying time periods and groups of people as follows:

In Phase I we see small red wild animals such as deer and gazelle, mostly in outline but occasionally with a light wash of solid infill, and small outline human figures in profile (Figures $5 \& 6$ ). These figures are very naturalistic and found only at one site, KK1. There is a sub or transitional phase with patterned infill added to some figures. This phase has art typical of hunter-gatherers.

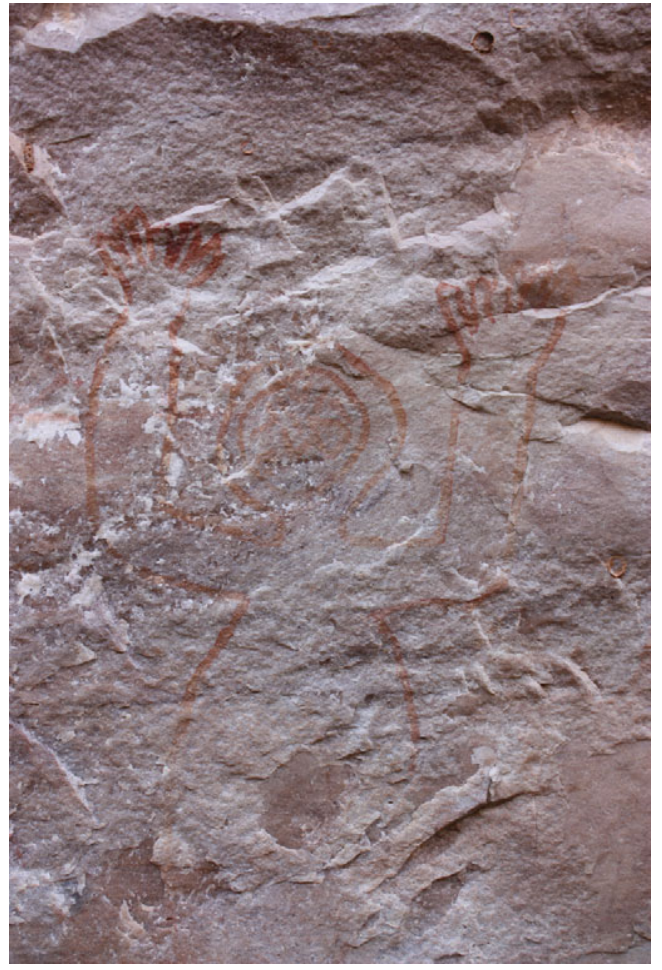

Figure 11. Large outline human-like figure with upraised arms.

Phase II is characterised by solid red human-like figures, animals and geometric designs (Figures $7 \& 8$ ). The humans are sometimes arranged together in repeated themes. When single, there are a few repeated poses, in obverse or profile, usually with both arms upraised. Sometimes these types of figures overlap. A red drawn cart seen with a small cow near it may be a diagnostic indicator. Note that Phase II figures are distributed right across panels while earlier and later figures are both fewer in number and concentrated in certain parts of panels. Animals in this phase are mostly domesticated, including goats, cattle and dogs. These properties, together with the abundant Iron Age pottery and burial structures discovered through recent systematic survey in the valley, suggest that this phase is likely associated with the Iron Age. The succession discerned in Figure 9, serves to place Phase II after Phase I.

To Phase III belong large outline animals and human-like figures, in varying shades of red and orange. Some have infill such as spots, as on a leopard depiction. Most human-like figures have upraised arms (Figure 11) but are different in posture, style and form from the solid figures of Phase II. Some figures have a cartoon-like quality. A mix of wild and domesticated animals is depicted. This phase is likely from the historic period.

Phase $I V$ is signalled by white hand-prints, tridents and other geometric designs owed to pilgrims visiting and marking sites (Figure 12). This art may have begun in the past couple of centuries and is still made today.

In Phase $V$ we have placed white rough human-like figures on rock walls that line fields (Figure 13) that may have a 'scarecrow' function. Dry pigment re-outlining of older figures, both red and white, also occurs, along with some initials/graffiti. These forms of rock marking are extremely recent and continue to be made. 


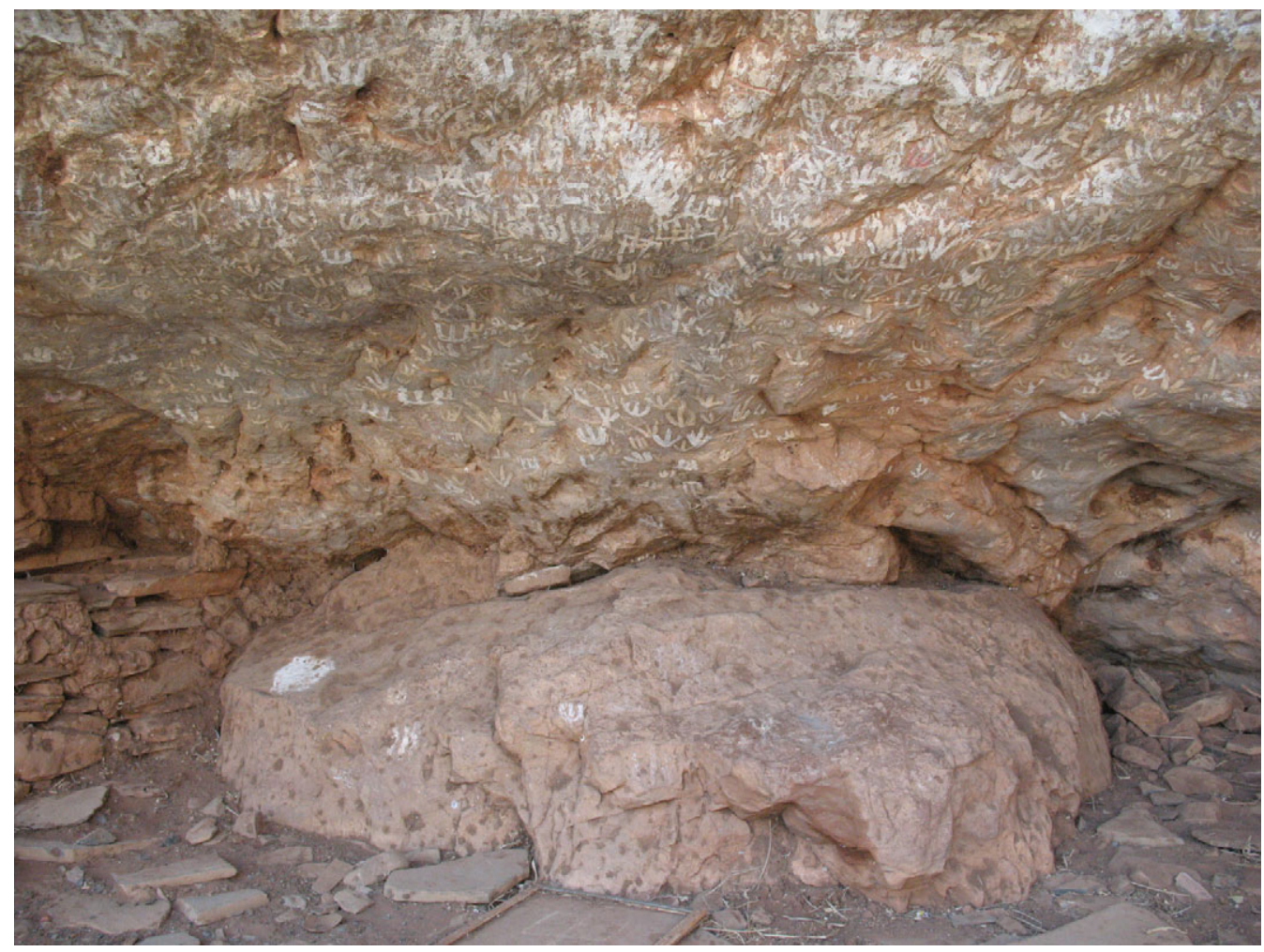

Figure 12. Recent pilgrim site with tridents, Katavani Kunta Valley.

\section{Kurnool pictographs in context}

The outline animal rock paintings that the early Kurnool area art (Phase I) most closely resemble are from Settavaray (see Figures 287, 295 and 305 in Neumayer 1993: 125-8), while some human figures from Benekal Forest - Hire Benakal are also similar (Figure 292 in Neumayer 1993: 126). Settavaray lies about $500 \mathrm{~km}$ to the south-east, between Tiruvannamalai and Pondicherry, while Benekal Forest - Hire Benakal is about $150 \mathrm{~km}$ west, upstream and near the Tungabhadra River. There also is a resemblance to some early animal paintings of the Bhimbetka area, far to the north (see Mathpal 1984, 1993: 15, Figure 19, 1993: Plate VI). However, these seem to be the only places where this form of art has survived. Some solid red wash infill Phase I animals are almost identical to a few paintings at Kethavaram, about $35 \mathrm{~km}$ north, with one so similar it could have been made by the same artist (Chandramouli 2003: 160, fig. 11.3).

The more recent Kurnool phases of rock art appear quite different to those of neighbouring states, or any other part of India, although some of the Phase II paintings are similar to those at nearby Kurnool area sites documented by Chandramouli (2002: 92-141) and Phase III paintings resemble some from other parts of Andhra Pradesh (see Chandramouli 2002). There is little similarity between Kurnool area rock art and that of Kerala (as in Mathpal 1998), although some similar changes in pictograph styles over time can be detected. 


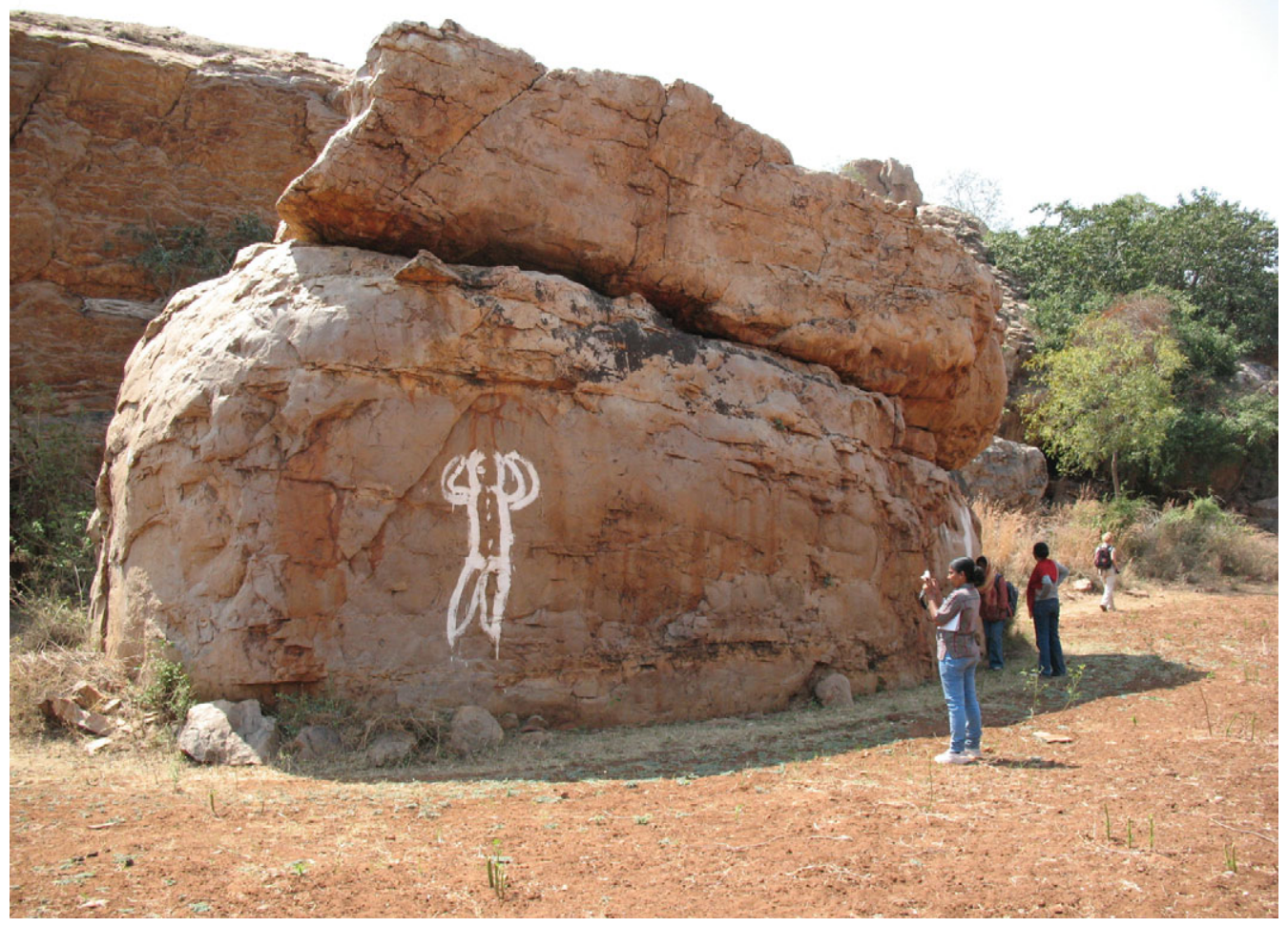

Figure 13. White rough human-like figures on rock walls that line fields, Katavani Kunta Valley.

Kurnool rock art also appears very different to that of Tamil Nadu (see Sridhar 2005) and Orissa (see Pradhan 2001).

A few sites in the Katavani Kunta and Yaganti valleys have depictions of stylised cattle forms more typical of Deccan Plateau/Karnataka rock art to the west (see Boivin 2004) and some sites in between (e.g. Budagavi rockshelter 4 and Dupadugattu rockshelter 2, in Chandramouli 2003: 164), suggesting some connections between people of these areas during the Iron Age. Stick-like linked human figures arranged in rows, which occur at Deccan Plateau sites and elsewhere (Malaiya 1992), are also found at a few sites in Kurnool (Figure 14). The diamond or lozenge pattern design found at KK1 appears to be widespread across India, either as a separate motif or as infill within figures (see Chandramouli 2002: Figures 35 and 37c; Neumayer 1992: Figures 2, 5, 7, 10, 1993: Figures 34-37; Pandey 1992: Figures 1-4; Tyagi1992), as well as an engraved motif on portable objects such as a stone core (Sonawane 1984, 1992; see also Brumm et al. 2006).

Early Kurnool rock art (Phase I) is dissimilar to most of the known rock art of India, other than that noted above. However, its style and form has strong similarities to Magdalenian rock art of Western Europe (see Clottes 1990, 2008; Sacchi 2003) and to the naturalistic outline paintings of the Jinsha River region of north-west Yunnan province, China (as in Taçon et al. 2010). A key feature of both of these art bodies is an elegance and ease imparted to outlines, which distinguishes this art from the heavy outlined animals of 


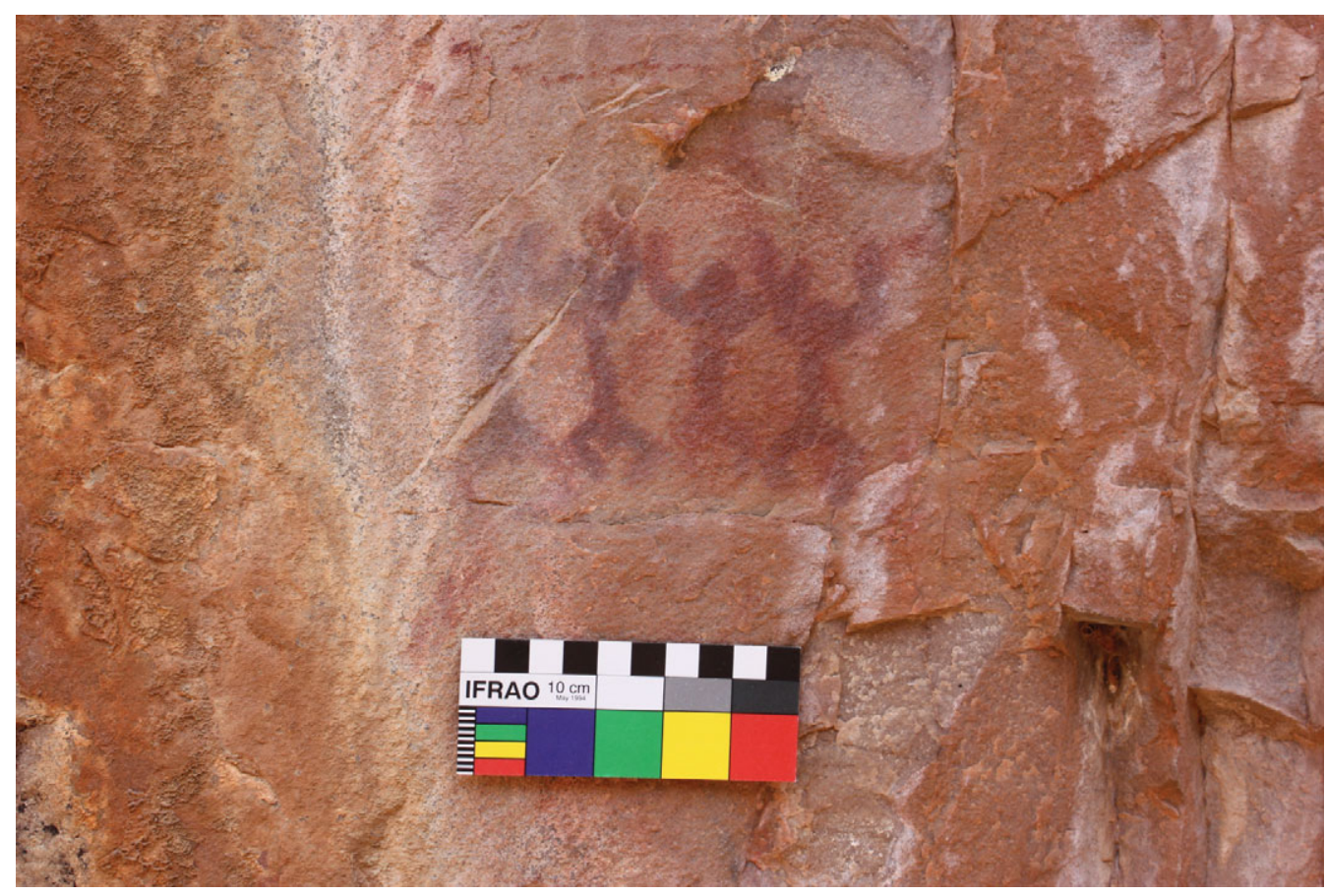

Figure 14. Linked human stick figures from a Katavani Kunta Valley site, similar to others found on the Deccan Plateau and other parts of India.

other periods (Giedion1969: 186). This also is true of Kurnool Phase I art. However, all three art bodies also have differences and are likely unrelated. Instead, aspects of human physiology, perception and shared forms of lifestyle (i.e. hunting/gathering) may account for the similarity (Halverson 1992; Watson 2009).

Most later Kurnool rock art (Phases II-V) reflects regional concerns and in situ development. Consequently, the more recent phases are very different from the rock art of other parts of India and beyond, though linkages to the Deccan Plateau rock art may reflect the emergence of more widely distributed cultural traditions, a phenomenon that might be linked to the spread of megalithic practices in the Iron Age.

\section{Conclusions}

Very little rock art has been directly dated in India but there are many regional sequences with good relative dates for some designs, styles and subject matter. An examination of preservation, overlapping imagery, landscape location, style and subject matter at sites near Kurnool has allowed us to work out a regional sequence for this region. Comparison with similar figures from other parts of India and beyond suggests the surviving Kurnool image sequence begins at least 10000 years ago.

The earliest surviving pictographs of the Kurnool area consist mainly of naturalistic outline paintings of animals and human-like figures. These paintings differ from most Indian rock art, and we conclude that they were made by hunter-gatherers. They were 
probably invented independently in India and are not directly related to similar-looking art in Europe or Yunnan, China. With the rise of agriculture, and of the subsequent increasingly hierarchical societies and political economies of the Iron Age (Boivin et al. 2008), new forms of rock art developed in situ. But influences from nearby parts of India can also be detected. These were much more concerned with the human form than previous art and may, in Kurnool, relate to the emergence of novel ritual traditions in which individuals and elite groups were demarcated and differentiated through new corporal and burial practices. By this period, influences from nearby parts of India can also be detected, and these may reflect in part the spread of new ideologies, and perhaps important changes to the hunting and gathering communities that occupied the area, as contacts with farmers expanded (see Petraglia et al. 2009b).

Rock art continued to be made through the historic period with new forms and styles emerging. In recent times, some sites have become focal points for pilgrims, who add their own marks to growing accumulations of abstract white trident-like and related designs. Some local villagers also re-outline older paintings and large, rough white human-like figures are made on rocky outcrops that line cultivated fields, serving a scarecrow-like function.

Further research will focus on better linking Kurnool's changing rock art tradition to broader landscape use and the results of nearby archaeological excavations, as well as radiometric dating. The incidence of a diamond pattern found at some Kurnool sites and at many other locations across India needs further exploration as it is associated with various time periods and some engraved stone tools. It appears to be a specifically Indian form of aesthetic expression with Pleistocene roots that links many groups of people across the sub continent together, a form of shared artistic heritage that is typically 'Indian' in character.

\section{Acknowledgements}

This research was funded by a grant awarded to Boivin by the Society for South Asian Studies and by grants awarded to Petraglia by the British Academy and the Leverhulme Trust. Korisettar acknowledges the Archaeological Survey of India for permission to conduct this work, and Petraglia the American Institute for Indian Studies for assistance. Griffith University is thanked for support and additional funding.

We also thank Somashekharayya Hiremath Balageri, Janardhana B., Sreelatha Damodaran, Michael Haslam, Hannah James, Sacha Jones, Jinu Koshy, Preston Miracle, Saritha N., Ranimole S.J and Kevin White for assistance in the field. Christopher Chippindale, Chris Clarkson, Pete Ditchfield, Dorian Fuller, Michael Haslam, Sacha Jones, Jinu Koshy, Rebecca McClung, Preston Miracle, K. Rajan, Ceri Shipton and P.C. Venkatasubbaiah are thanked for various helpful discussions. Photographs are by P.S.C. Taçon.

\section{References}

ALLCHIN, F.R. 1963. Neolithic cattle-keepers of south India: a study of the Deccan ashmounds. Cambridge: Cambridge University Press.

Allchin, F.R. \& B. Allchin. 1994-95. Rock art of North Karnataka. Bulletin of the Deccan College Post-Graduate and Research Institute 54-55: 313-39.

BEDNARIK, R.G. 2002. The development of Indian rock art studies since Independence, in S. Settar \& R. Korisettar (ed.) Indian archaeology in retrospect. Volume 1: Prehistory, archaeology of South Asia: 353-75. Delhi: Manohar.
BEDNARIK, R. \& K.K. CHAKRAVARTY. 1997. Indian rock art and its global context. New Delhi: Shri Jainendra Press.

BLINKHORN, J. 2008. In which context does symbolic behavior first manifest in the archaeological record: a case study from Kurnool District, India. Unpublished MPhil dissertation, University of Cambridge.

BoIvin, N. 2004. Rock art and rock music: petroglyphs of the south Indian Neolithic. Antiquity 78: 38-53. 
Boivin, N., A. BRumm, H. Lewis, D. Robinson \& R. KorisetTAR. 2007. Sensual, material, and technological understanding: exploring prehistoric soundscapes in south India. Journal of the Royal Anthropological Institute 13: 267-94.

Boivin, N., D. Fuller, R. Korisettar \& M. Petraglia. 2008. First farmers in south India: the role of internal processes and external influences in the emergence of the earliest settled societies. Pragdhara 18: 179-200

Boivin, N., J. Hampson, J. BlinKhorn, R. Korisettar \& M. Petraglia. 2009. Re-examining rock art studies in India: a case study from Kurnool District, Andhra Pradesh, in K. Paddayya, P.P. Joglekar, K.K. Basa \& R. Sewant (ed.) Recent research trends in South Asian archaeology: 261-78. Pune: Deccan College.

Brooks, R. \& V.S. WaKanKar. 1976. Stone Age painting in India. New Haven (CT): Yale University Press.

Brumm, A., N. Boivin \& R. Fullagar. 2006. Signs of life: engraved stone artefacts from Neolithic South India. Cambridge Archaeological Journal 16(2):165-90.

Chakravarty, K.K. (ed.) 1984. Rock-art of India: paintings and engravings. New Delhi: Arnold-Heinemann.

CHAKRAVERTY, S. 2003. Rock art studies in India: a historical perspective. Kolkata: The Asiatic Society.

CHANDramoul, N. 2002. Rock art of south India: with special reference to Andhra Pradesh. Delhi: Bharatiya Kala Prakashan.

- 2003. Rock art of Andhra Pradesh, in M.L.K. Murty (ed.) Pre-and Protohistoric Andhra Pradesh up to 500 $B C$ : 148-73. Chennai: Orient Longman.

Clarkson, C., M. Petraglia, R. Korisettar, M. Haslam, N. Boivin, A. Crowther, P. Ditchfield, D. Fuller, P. Miracle, C. Harris, K. Connell, H. James \& J. Koshy. 2009. The oldest and longest enduring microlithic sequence in India: 35000 years of modern human occupation and change at the Jwalapuram Locality 9 rockshelter. Antiquity 83: 326-48.

Clottes, J. 1990. The parietal art of the late Magdalenian. Antiquity 64: 527-48.

- 2008. Cave art. London: Phaidon Press Limited.

Cockburn, J. 1899. Cave drawings in the Kaimur range, Northwest Provinces. Journal of the Royal Asiatic Society 1899: 89-97.

FranKE, A.H. 1902. Notes on rock carvings from Lower Ladakh. The Indian Antiquary 31: 398-401.

GHOSH, R.S.M. 1998. Rock-paintings and other antiquities of prehistoric and later times. New Delhi: Archaeological Survey of India.
Giedion, S. 1969. The outline in the early beginnings of art. Leonardo 2(2): 181-92.

Gordon, D.H. 1951. The rock engravings of Kupgalla Hill, Bellary, Madras. Man 51: 117-19.

Gupta, S., S.S. RaI, K.S. PraKasam, D. SRINAgESH, B.K. Bansal, R.K. Chadha, K. Priestley, \& V.K. GAUR. 2003. The nature of the crust in southern India: implications for Precambrian crustal evolution. Geophysical Research Letters 30: 141-49.

HALVERSON, J. 1992. The first pictures: perceptual foundations of Paleolithic art. Perceptions 21: 389-404.

MalaiYA, S. 1992. Hand-in-hand dancing in Indian rock art and its continuities, in M.J. Morwood \& D.R. Hobbs (ed.) Rock art and ethnography: 60-66. Melbourne: Australian Rock Art Research Association.

MathPAL, Y. 1984. Prehistoric rock paintings of Bhimbetka Central India. New Delhi: Abhinav Publications.

- 1993. Deer in rock art of India, in G. Camuri, A. Fossati \& Y. Mathpal (ed.) Deer in rock art of India and Europe: 1-53. New Delhi: Indira Gandhi National Centre for the Arts.

- 1998. Rock art in Kerala. New Delhi: Indira Gandhi National Centre for the Arts.

MURTY, M.L.K. 1985. Ethnoarchaeology of the Kurnool Cave areas, South India. World Archaeology 17(2):192-205.

- 1992. Hunter-gatherers, pastoralists and the state in southwestern Andhra Pradesh, South India, in F. Audouze (ed.) Ethnoarchéologie: justification, problèmes, limites. Actes des rencontres 17-18-19 octobre 1991, XIIe Rencontres Internationales d'Archéologie et d'Histoire d'Antibes: 326-38. Juan-les-Pins: Editions APDCA.

- 2003a. Physiography and environment, in M.K.L. Murty (ed.) Pre- and Protohistoric Andhra Pradesh up to 500 BC: 9-28. Chennai: Orient Longman.

- (ed.) 2003b. Pre-and Protohistoric Andhra Pradesh up to 500 BC. Chennai: Orient Longman.

Neumayer, E. 1983. Prehistoric Indian rock paintings. Delhi: Oxford University Press.

- 1992. Rock art in India, in M. Lorblanchet (ed.) Rock art in the Old World: 215-47. New Delhi: Indira Gandhi National Centre for the Arts.

- 1993. Lines on stone: the prehistoric rock art of India. New Delhi: Manohar.

PANDEY, S.K. 1992. Central Indian rock art, in M. Lorblanchet (ed.) Rock art in the Old World: 249-72. New Delhi: Indira Gandhi National Centre for the Arts. 
Petraglia, M., R. Korisettar, N. Boivin, C. Clarkson, K. Cunningham, P. Ditchfield, S. Jones, J. Koshy, M.M. LAHr, C. OPPENHEIMER, D. Pyle, R. Roberts, J.-L. SChWEnninger, L. ARnOld \& K. White. 2007. Middle Paleolithic assemblages from the Indian Subcontinent before and after the Toba super-eruption. Science 317: 114-16.

Petraglia, M., C. Clarkson, N. Boivin, M. Haslam, R. Korisettar, G. Chaubey, P. Ditchfield, D. Fuller, H. James, S. Jones, T. Kivisild, J. Koshy, M.M. Lahr, M. Metspalu, R. Roberts \& L. ARNOLD. 2009a. Population increase and environmental deterioration correspond with microlithic innovations in South Asia ca. 35,000 years ago. Proceedings of the National Academy of Sciences. 106(30): 12261-12266.

Petraglia, M., R. Korisettar, M.K. Bai, N. Boivin, B. Janardhana, C. Clarkson, K. Cunningham, P. Ditchfield, D. Fuller, J. Hampson, M. Haslam, S. Jones, J. Koshy, P. Miracle, C. OpPenheImer, R. Roberts \& K. White. 2009b. Human occupation, adaptation and behavioral change in the Pleistocene and Holocene of South India: recent investigations in the Kurnool District, Andhra Pradesh. Eurasian Prehistory 6(1-2): 119-66.

Pradhan, S. 2001. Rock art in Orissa. New Delhi: Aryan Books International.
SACCHI, D. 2003. Le Magdalénien. Paris: Maison des Roches.

SonAWANE, V.H. 1984. An important evidence to date paintings of Mesolithic Period, in K.K. Chakravarty (ed.) Rock-art of India: paintings and engravings: 61-63. New Delhi: Arnold-Heinemann.

- 1992. Significance of the Chandravati engraved core in the light of prehistoric art of India, in M. Lorblanchet (ed.) Rock art in the Old World: 273-83. New Delhi: Indira Gandhi National Centre for the Arts.

SRIDHAR, T.S. 2005. Rock art of Tamil Nadu. Chennai: State Department of Archaeology, Government of Tamil Nadu.

TAÇON, P.S.C., G. LI, D. YANG, S.K. MAY, H. LiU, M. Aubert, X. Ji, D. Curnoe \& A.I.R. Herries. 2010. Naturalism, nature and questions of style in Jinsha River rock art, northwest Yunnan, China. Cambridge Archaeological Journal. 20(1): 67-86.

TYAGI, G.S. 1992. Decorative intricate patterns in Indian rock art, in M. Lorblanchet (ed.) Rock art in the Old World: 303-17. New Delhi: Indira Gandhi National Centre for the Arts.

Watson, B. 2009. Universal visions: Neuroscience and recurrent characteristics of world palaeoart. Unpublished PhD dissertation, University of Melbourne. 